\title{
Is ascites caused by impaired hepatic inactivation of blood borne endogenous opioid peptides?
}

\author{
J R THORNTON, H DEAN, AND M S LOSOWSKY \\ From the Department of Medicine, St James's University Hospital and Department of Pharmacology, \\ University of Leeds, Leeds
}

SUMMARY Methionine enkephalin and catecholamines were measured in carefully collected plasma samples from 25 patients with cirrhosis and ascites, and 25 with cirrhosis without ascites, 15 disease and 15 healthy controls. Methionine enkephalin was invariably raised in the ascites group, the median value being 4.6-6.9 times that of the other three groups. Similarly, in the ascites group, median noradrenaline was increased $2 \cdot 5-4.2$ and median adrenaline 1.8-2.5 times that of the other groups. Plasma methionine enkephalin is considerably raised in patients with cirrhotic ascites and has actions which could enable it to be an initiating factor of ascites formation.

After the discovery of methionine and leucine enkephalins in $1975,{ }^{\prime}$ more than 10 endogenous opioid peptides have been described. ${ }^{2}$ These peptides have multiple actions, exerted via at least three classes of receptors, mu, kappa, and delta. ${ }^{2}$ Many opioid peptides have been shown to circulate in the bloodstream $^{3-6}$ where they may act as hormones. ${ }^{57}$ We have suggested that the liver may play a major role in the inactivation, largely by enzymatic degradation, of blood borne opioid peptides comprising eight or fewer amino acids, such as the pentapeptide methionine enkephalin. ${ }^{8}$ If so, six opioid peptides (methionine enkephalin, methionine enkephalin-arg-phe, methionine enkephalin-arg-glyleu, adrenorphin, leucine enkephalin and dynorphin 1-8) may be found to be increased in the plasma of patients with liver disease.

The very wide distribution of methionine enkephalin receptors includes blood vessel sites. ${ }^{910}$ Like opiates, ${ }^{11}$ opioid peptides are potent vasodilators. ${ }^{12-16}$ Failure of the diseased liver to metabolise a vasodilator substance has long been proposed. ${ }^{17}$ Because cardiac output in patients with decompensated cirrhosis tends to be high, ${ }^{17-19}$ vasodilatation would seem the probable explanation for

Address for correspondence: Dr J R Thornton, Dept of Medicine, St James's Hospital, Leeds LS9 TTF.

Received for publication 7 April 1988. the low peripheral vascular resistance, low arterial pressure and increased cutaneous blood flow often found in such patients. ${ }^{17-21}$

We propose that, in cirrhosis, chronicallyimpaired, hepatic inactivation of methionine enkephalin and possibly other small opioid peptides, may cause or contribute to vasodilatation and that one important consequence may be the development of ascites, arising largely as a result of an imperfect homeostatic attempt to maintain systemic arterial pressure. Thus, the sodium and water retention of ascites may be mediated largely by secondary activation of the sympathetic nervous system and adrenal medullae. A similar mechanism may stimulate the non-osmotic release of vasopressin. Opioid peptide initiated lymphatic leakage may also contribute to ascites formation. This hypothesis is outlined in Figure 1 and discussed in more detail below.

\section{Methods}

SUBJECTS

As an initial investigation of this hypothesis, we studied 50 patients with biopsy proven cirrhosis of the liver. Half of these patients had ascites, with or without peripheral oedema (group I). The ascites was unequivocally present on clinical examination, confirmed and shown to be free of infection by diagnostic aspiration. The remaining 25 patients with cirrhosis 


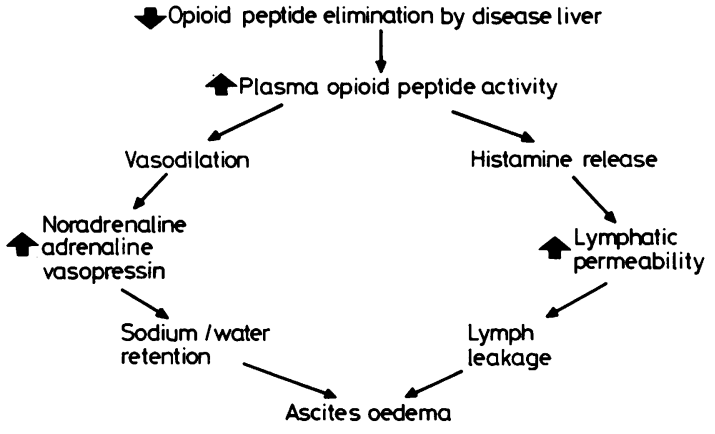

Fig. 1 Proposed opioid peptide pathogenesis of the fluid retention of hepatic cirrhosis. Thick arrows indicate direction of change.

did not have clinically apparent ascites and were not taking any diuretics (group II). These patients were compared with 15 disease controls (three congestive cardiac failure, three chronic asthma, three chronic pancreatitis, two untreated coeliac disease, two insulin-dependent diabetes mellitus, one chronic intestinal pseudo-obstruction, one pneumococcal pneumonia complicating carcinoma of the bronchus) who had normal bilirubin and alanine aminotransferase and no other evidence of liver disease (group III) and with 15 healthy controls (group IV). In addition, three further subjects with cirrhosis were studied before and after the development of ascites. All the subjects with ascites were hospital inpatients and taking a sodium restricted diet of approximately $40 \mathrm{mmol} / \mathrm{day}$. None of the subjects were taking any drugs which are known or likely to affect plasma methionine enkephalin or catecholamines. In particular, no subject was taking $\beta$-adrenergic blockers.

Subjects were excluded from the study for the following reasons: (1) the presence of ascites was equivocal. (2) They had had a previous episode of ascites and still required diuretics to maintain them free from further fluid retention. (3) They had a plasma creatinine greater than the upper limit of normal for our laboratory. (4) They had had a gastrointestinal bleed within the previous five days. (5) They had been drinking alcohol within the previous three weeks.

Pulse rate and arterial pressure were measured just before blood sampling.

\section{Sample collection}

Venous blood was collected with the subjects at rest in a sitting position, a heparinised cannula having been inserted 20 minutes earlier. The samples for methionine enkephalin measurement were collected using chilled syringes and chilled bottles containing citric acid. They were transferred rapidly to a pre- cooled centrifuge at $4^{\circ} \mathrm{C}$ and spun at $3000 \mathrm{rpm}$ for 10 minutes. The plasma obtained was divided into aliquots, acidified further to $\mathrm{pH} 3 \cdot 0-4 \cdot 0$ with molar hydrochloric acid and stored at $-70^{\circ} \mathrm{C}$. Part of the blood sample obtained was sent for measurement of creatinine, urea, electrolytes, and liver function tests.

As the pentapeptide enkephalins have a half life of only eight minutes in normal plasma, ${ }^{22} 23$ preliminary investigations were done to ensure preservation of methionine enkephalin. Immediate chilling of the blood sample, using heparin as the anticoagulant, was found to be inadequate. Aprotinin (Trasylol) has been suggested to preserve the peptide ${ }^{2+}$ but we, like others, ${ }^{625}$ found it to be ineffective, even in association with chilling of the sample. Using it as a preservative gave methionine enkephalin values not significantly different from those when heparin alone was used. A combination of enzyme inhibitors may be necessary to prevent methionine enkephalin degradation in plasma ${ }^{7}$ and these inhibitors are expensive. As an aminopeptidase which inactivates enkephalins is denatured by a $\mathrm{pH}$ below $5 \cdot 5,{ }^{26}$ we developed a technique using immediate chilling of the sample and its acidification to $\mathrm{pH} 5 \cdot 0-5 \cdot 5$ using citric acid. This procedure was shown to preserve more than $90 \%$ of methionine enkephalin for at least one hour. Addition of larger enkephalins containing the methionine enkephalin sequence (methionine enkephalin arg-phe, methionine enkephalin arggly-leu, peptide E) to chilled, citric acid containing plasma samples did not result in increased methionine enkephalin values when measured by either the radioimmunoassay or high performance liquid chromatography, indicating that acidification does not promote and may prevent processing of larger enkephalins to methionine enkephalin. Further acidification of the plasma sample to $\mathrm{pH}$ 3.0-4.0 and storage at $-70^{\circ} \mathrm{C}$ was shown to maintain methionine enkephalin for over a year.

\section{Radioimmunoassay}

Methionine enkephalin was partially separated from other plasma constituents using C18 Sep-Pak columns primed with methanol and water. One millilitre of the sample was added to the columns which were then rinsed with $4 \%$ acetic acid and eluted using methanol. The dried eluate was reconstituted with bovine serum albumin-phosphate buffer and $200 \mu \mathrm{l}$ was assayed in duplicate. $100 \mu \mathrm{l}$ of $I^{125}$-methionine enkephalin was mixed with the sample, standard and non-specific binding tubes and incubated for 17 hours at $4^{\circ} \mathrm{C}$. One hundred microlites of rabbit gamma globluin carrier was then added, followed by $500 \mu \mathrm{l}$ saturated ammonium sulphate to separate bound from free tracer. After 
standing for 20 minutes, the tubes were centrifuged at $1000 \mathrm{~g}$ for 10 minutes and the supernatant decanted. The radioactivity of the precipitate was counted in a gamma scintillation counter for five minutes. The percentage of bound tracer divided by the tracer's total counts was calculated for each sample and the quantity of methionine enkephalin determined by reference to the standard curve. The antibody, tracer, and reagents were purchased from Immuno Nuclear Corporation, Stillwater, Minnesota, USA.

Our validation studies on the assay showed parallelism, when either pure methionine enkephalin or plasma samples containing high quantities of the peptide were serially diluted. We found a recovery rate of $86 \%$ and within- and between-assay coefficients of variation of $8 \%$ and $11 \%$ respectively. Nonspecific binding ranged from $6 \cdot 5-7 \cdot 9 \%$. Minimum sensitivity was $50 \mathrm{pmol} / \mathrm{l}(30 \mathrm{pg} / \mathrm{ml})$. Using pure peptides purchased from either Bachem Inc or Peninsula Laboratories, the antibody was shown to

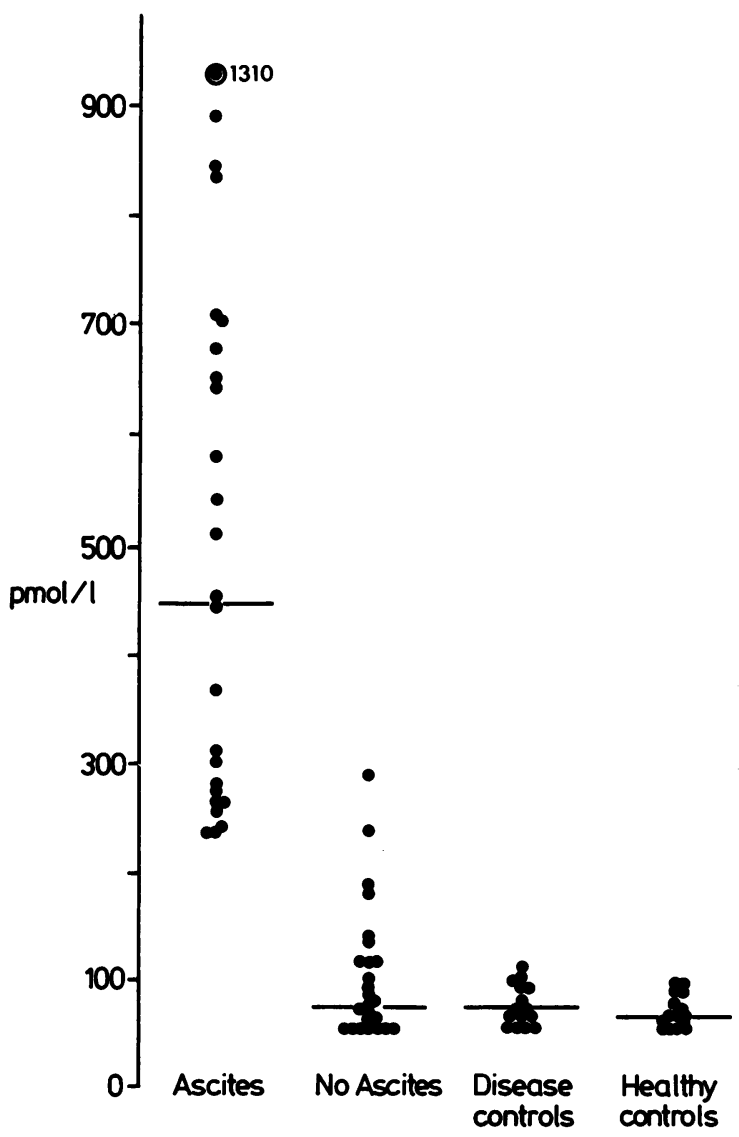

Fig. 2 Plasma methionine enkephalin in the four groups of subjects. Medians indicated by horizontal bars. be highly specific for methionine enkephalin. Its cross reactivity was: leucine enkephalin $5 \%$, methionine enkephalin-arg-phe $3 \%$, gly-gly-phe-met $2 \%$, and methionine enkephalin-arg-gly-leu, dynorphin 1-8, dynorphin 1-17, peptide E, B-endorphin all $<0.01 \%$. These cross reactivity and reproducibility findings are highly comparable with those of others using the same antibody. ${ }^{27} 28$ The specificity of the antibody for pentapeptide methionine enkephalin was confirmed further by reverse phase, high performance, liquid chromatography. A 6000 A solvent delivery system with UGK universal injector, A460 electrochemical detector, 730 data module and mu Bonda Pak C18 column purchased from Waters Associates were used. Plasma samples which the radioimmunoassay indicated to contain high amounts of methionine enkephalin, were injected with a solvent system of $23 \%$ acetonitrile and $77 \%$ $0 \cdot 1 \mathrm{M}$ sodium dihydrogen phosphate buffer. A peak corresponding in site to that of standard methionine enkephalin was observed and collected. This fraction, when measured by the radioimmunoassay, produced values for methionine enkephalin corresponding well with that determined chromatographically. Compared with this fraction, immediately adjacent small peaks contained $<2 \%$ methionine enkephalin immunoreactivity.

Noradrenaline - and adrenaline were measured radioenzymatically. ${ }^{29}{ }^{30}$ The statistical significance of differences was determined by the Mann-Whitney $U$ test for the plasma measurements and by the paired $t$ test for heart rate and arterial pressure.

\section{Results}

Plasma methionine enkephalin was invariably raised in the patients with ascites (Fig. 2), with a range of 2.5 to 13.7 times the upper limit of normal. Its median value in the ascites patients was 4.6 to 6.9 times the median values in the other three groups (Table). There was no significant difference in methionine enkephalin between the 18 patients who were taking spironolactone, median $390 \mathrm{pmol} / \mathrm{l}$, range 235-1315 $(223 \mathrm{pg} / \mathrm{ml}, 135-755)$ and the seven who were not, median $495 \mathrm{pmol} / \mathrm{l}$, range $260-880(284 \mathrm{pg} / \mathrm{ml}, 150-$ 505). In three further patients with cirrhosis who developed ascites during the study, methionine enkephalin rose in all of them from 80,95 , and 175 $\mathrm{pmol} / 1$ to 470,255 , and $660 \mathrm{pmol} / 1$ respectively (45, 55 , and $100 \mathrm{pg} / \mathrm{ml}$ to 270,145 , and $380 \mathrm{pg} / \mathrm{ml}$ ).

In the patients with ascites, the median value of noradrenaline was increased 2.5 to 4.2 times and median adrenaline concentration 1.8 to 2.5 times that of the remaining groups (Table). The patients with ascites also had a lower plasma albumin and higher plasma creatinine compared with the other groups. 
Table Plasma methionine enkephalin, noradrenaline, adrenaline, albumin, creatinine, heart rate, and mean arterial pressure in the four groups of subjects. Data expressed as medians with range.

\begin{tabular}{lcccc}
\hline & Ascites $(I)$ & No Ascites $(I I)$ & Disease controls $($ III) & Healthy controls $($ IV) \\
\hline Methionine enkephalin $(\mathrm{pmol} / \mathrm{l})$ & $445(235-1315)^{*}$ & $95(50-285)$ & $73(50-110)$ & $65(50-95)$ \\
Noradrenaline $(\mathrm{pmol} / \mathrm{l})$ & $7120(1790-20000)^{*}$ & $2820(1600-5940) \ddagger$ & $1940(710-6700)$ & $1740(910-4680)$ \\
Adrenaline $(\mathrm{pmol} / \mathrm{l})$ & $980(300-2500)^{*}$ & $435(110-1580)$ & $330(190-1030)$ & $300(110-900)$ \\
Albumin $(\mathrm{g} / \mathrm{l})$ & $31(23-43)^{*}$ & $42(33-48)$ & $38(30-45) \ddagger$ & $42(39-48)$ \\
Creatinine $(\mu \mathrm{mol} / /)$ & $86(66-117)^{*}$ & $70(47-85)$ & $73(52-87)$ & $68(51-79)$ \\
Heart rate $(\mathrm{beats} / \mathrm{min})$ & $92(84-105) \dagger$ & $76(66-95)$ & $81(68-121)$ & $69(59-85)$ \\
Mean arterial pressure $(\mathrm{mmHg})$ & $97(93-104) \ddagger$ & $102(94-110)$ & $104(87-113)$ & $109(102-121)$ \\
\hline
\end{tabular}

Significant differences: ${ }^{*} \mathrm{p}<0.001 ; \nmid \mathrm{p}<0.01 ; \neq \mathrm{p}<0.05$.

Conversion factors: $\mathrm{pmol} / \mathrm{l}$ to $\mathrm{pg} / \mathrm{ml}$ : methionine enkephalin $\times 0 \cdot 574$, noradrenaline $0 \cdot 170$, adrenaline $0 \cdot 184$.

In the 50 patients with cirrhosis (groups I and II), methionine enkephalin was directly correlated with noradrenaline $(\mathrm{r}=0.359, \mathrm{p}<0.01)$, adrenaline $(\mathrm{r}=0.491, \mathrm{p}<0.001)$, and creatinine $(\mathrm{r}=0.331$, $\mathrm{p}<0.02)$. In addition, noradrenaline directly correlated with adrenaline $(\mathrm{r}=0.381, \mathrm{p}<0.01)$ and creatinine $\quad(r=0.323, \quad p<0.02)$ Methionine enkephalin $(r=-0.434, p<0.002)$, noradrenaline $(\mathrm{r}=-0.655, \mathrm{p}<0 \cdot 001)$, and adrenaline $(\mathrm{r}=-0.457$, $\mathrm{p}<0.001)$ were all inversely correlated with plasma albumin.

There were no significant differences between the four groups of subjects in either sex distribution or age.

\section{Discussion}

This study shows that methionine enkephalin is increased considerably in the plasma of patients with hepatic cirrhosis and ascites. This finding cannot be explained by these patients being more ill than the remainder, as most were chronically rather than acutely unwell, and apparently no more so than those patients in the disease control group. Furthermore, some of the relatively well subjects with cirrhosis without ascites also had moderately raised plasma methionine enkephalin. Acute blood loss causes release of this opioid peptide from the adrenal glands. ${ }^{27} 28$ All the subjects with cirrhosis, however, were haemodynamically stable.

The source(s) of circulating methionine enkephalin is unclear. It can be released by the adrenal glands ${ }^{31}$ and is present in sympathetic nerves ${ }^{32}$ and the gut. ${ }^{33}$ Bilateral adrenalectomy has no effect on the normal concentration of methionine containing enkephalins, ${ }^{34}$ however, and we have found markedly raised plasma methionine enkephalin in the presence of normal sympathetic tone in patients with acute liver disease. ${ }^{35}$

Beta-endorphin, a much larger opioid peptide whose plasma concentration, like methionine enkephalin, ${ }^{2728}$ rises in response to acute hypovolaemaemia, ${ }^{36,37}$ is not increased in patients with cirrhosis and ascites. ${ }^{38}$ This suggests that the rise in plasma methionine enkephalin is not a non-specific response to vascular underfilling in these patients. The data clearly do not permit a definite conclusion, however, as to whether the increase in plasma methionine enkephalin in the patients with ascites is caused by increased secretion, diminished hepatic inactivation or both.

Like opiates, " opioid peptides are potent vasodilators $^{12-16}$ and receptor sites for methionine enkephalin include splanchnic blood vessels. ${ }^{910}$ We propose that increased plasma methionine enkephalin and possibly other small opioid peptides may cause or contribute to vasodilatation and thereby initiate increased sympathetic tone (indicated by raised plasma noradrenaline, ${ }^{30-11}$ ) adrenaline secretion, and non-osmotic vasopressin release $^{42}$ in a homeostatic attempt to maintain systemic arterial pressure.

Evidence that vasodilatation may initiate raised plasma catecholamines and ascites formation was provided by a recent study in which patients with refractory ascites had their ascitic fluid recirculated into their vascular compartment by peritoneovenous shunting. ${ }^{43}$ This procedure produced a marked natriuresis and diuresis, and a return of raised plasma catecholamines to normal. Despite these changes, the patients remained hypotensive with a low peripheral vascular resistance.

Raised plasma catecholamines in cirrhosis are a consequence of increased secretion rather than diminished clearance. ${ }^{445}$ In decompensated cirrhosis, increased renal artery resistance reduces renal blood flow, and intrarenal haemodynamics are deranged. ${ }^{46}$ Catecholamines are capable of causing such perturbations in renal perfusion ${ }^{47-49}$ and may, thereby, promote sodium and water retention in decompensated cirrhosis. ${ }^{5051}$

Leakage of lymph from the hepatic lymphatics 
into the peritoneum may contribute to ascites formation. ${ }^{52}$ Histamine, even in low doses, increases hepatic lymph flow and its protein content by enhancing the permeability of the endothelial cells lining the sinusoids. ${ }^{53}$ As opioid peptides stimulate histamine release ${ }^{5455}$ it is possible that they may also promote ascites by permitting egress of hepatic lymph.

In conclusion, this hypothesis provides a fundamentally simple explanation for many of the abnormalities believed to be important in the fluid retention of cirrhosis. The existence of opioid peptide antagonists provides a means of testing the hypothesis and offers the possibility of improved treatment of hepatic ascites.

\section{References}

1 Hughes J, Smith TW, Kosterlitz HW, Fothergill LA, Morgan BA, Morris HR. The identification of endogenous opioid pentapeptides. Nature 1975; 258: 577-9.

2 Imura H, Kato Y, Nakai Y, et al. Endogenous opioids and related peptides: from molecular biology to clinical medicine. J Endocrinol 1985; 107: 147-57.

3 Nakao K, Nakai Y, Oki S, Horii K, Imura H. Presence of immunoreactive b-endorphin in normal human plasma. A concomitant release of b-endorphin with adrenocorticotropin after metyrapone administration. J Clin Invest 1978; 62: 1395-8.

4 Clement-Jones V, Lowry PJ, Rees LH, Besser GM. Met-enkephalin circulates in human plasma. Nature 1980; 283: 295-7.

5 Boarder MR, Erdelyi E, Barchas JD. Opioid peptides in human oplasma: evidence for multiple forms. J Clin Endocrinol Metab 1982; 54: 715-20.

6 Ryder SW, Eng J. Radioimmunoassay of leucineenkephalin-like substance in human and canine plasma. $J$ Clin Endocrinol Metab 1981; 52: 367-9.

7 Corbett AD, Patterson SJ, McNight AT, Magnan J, Kosterlitz HW. Dynorphin 1-8 and dynorphin 1-9 are ligands for the $x$-subtype of opiate receptor. Nature 1982; 299: 79-81.

8 Thornton JR, Losowsky MS. Is plasma methionine enkephalin a mediator of some of the clinical manifestations of acute liver failure? J Hepatol 1987; 4: P15.

9 Illes P, Ramme D, Starke K. Inhibition of neuroeffector transmission in the rabbit mesenteric artery by [met's] enkephalin. Eur J Pharmacol 1985; 107: 397-8.

10 Yamamoto Y, Hotta K, Matsuda T. Effect of methionine-enkephalin on the spontaneous electrical and mechanical activity of the smooth muscle of the rat portal vein. Life Sci 1984; 34: 993-9.

11 Zelis R, Mansour EJ, Capone RJ, Mason DT, Kleckner R. The cardiovascular effects of morphine. The peripheral capacitance and resistance vessels in human subjects. J Clin Invest 1974; 54: 1247-58.

12 Grossman A, Clement-Jones V. Opiate receptors: enkephalins and endorphins. Clin Endocrinol Metab 1983; 12: 31-56.

13 Altura BT, Altura BM, Quirion R. Identification of benzomorphan- $x$ opiate receptors in cerebral arteries which subserve relaxation. Br J Pharmacol 1984; 82: 459-66.

14 Szabo B, Hedler L, Ensinger H, Starke K. Opioid peptides decrease noradrenaline release and blood pressure in the rabbit at peripheral receptors. NaunynSchmiedeberg's Arch Pharmacol 1986; 332: 50-6.

15 Pasanisi F, Sloan L, Rubin PC. Cardiovascular properties of metkephamid, a $\delta$ opioid receptor agonist, in man. Clin Sci 1985; 68: 209-13.

16 Hanbauer I, Kelley GD, Saiani L, Yang HYT. [Met ${ }^{5}$ ]enkephalin-like peptides of the adrenal medulla: release by nerve stimulation and functional implications. Peptides 1982; 3: 469-73.

17 Murray JF, Dawson AM, Sherlock S. Circulatory changes in chronic liver disease. Am J Med 1958; 24: 358-67.

18 Kontos HA, Shapiro W. Page Mauck H, Patterson JL, Jr. General and regional circulatory alterations in cirrhosis of the liver. Am J Med 1964; 37: 526-35.

19 Ring-Larsen H, Hesse B, Henriksen JH, Christensen NJ. Sympathetic nervous activity and renal and systemic hemodynamics in cirrhosis: plasma norepinephrine concentration, hepatic extraction and renal release. Hepatology 1982; 2: 304-10.

20 Bernardi M, Trevisani F, Santini C, et al. Plasma norepinephrine, weak neurotransmitters and renin activity during active tilting in liver cirrhosis: relationship with cardiovascular homeostasis and renal function. Hepatology 1983; 3: 56-64.

21 Martini GA, Hagemann JE. Uber fingernagelveranderungen bei lebercirrhose als folge veranderter peripherer durchblutung. Klin Wochenschr 1956; 34: 25-31.

22 Roscetti G, Possenti R, Bassano E, Roda LG. Mechanisms of leu-enkephalin hydrolysis in human plasma. Biochem Res 1985; 10: 1393-404.

23 Boarder MR, McArdle W. Breakdown of small enkephalin derivatives and adrenal peptide $E$ by human plasma. Biochem Pharmacol 1986; 35: 1043-7.

24 Clement-Jones V, Lowry PJ, Rees LH, Besser GM. Development of a specific extracted radioimmuno-assay for methionine-enkephalin in human plasma and cerebrospinal fluid. J Endocrinol 1980; 86: 231-43.

25 Aloyo VJ, Mousa SA, Van Loon GR. Stabilization of methionine-enkephalin in human and rat blood. Life Sci 1986; 39: 21-8.

26 Coletti-Previero M-A, Mattras H, Descamps B, ColettiPreviero A. Purification and substrate characterization of a human enkephalin-degrading aminopeptidase. Biochem Biophys Acta 1981; 657: 122-7.

27 Engeland WC, Bereiter DF, Gann DS. Sympathetic control of adrenal secretion of enkephalins after hemorrhage in awake dogs. Am J Physiol 1986; 251: R341-8.

28 Farrell LD, Harrison TS, Demers LM. Immunoreactive met-enkephalin in the canine adrenal; response to acute hypovolemic stress. Proc Soc Exp Biol Med 1983; 173: 515-8.

29 Da Prada M, Zurcher G. Simultaneous radioenzymatic determination of plasma and tissue adrenaline, noradrenaline and dopamine within the femtomole range. Life Sci 1976; 19: 1161-74. 
30 McKechnio K, Dean HG, Furman BL, Parratt JR. Plasma catecholamines during endotoxin infusion in conscious unrestrained rats: Effects of adrenal demedullation and/or guanethidine. Circ Shock 1985; 17: 85-94.

31 Chaminade M, Foutz AS, Rossier J. Co-release of enkephalins and precursors with catecholamines by the perfused cat adrenal in-situ. Life Sci 1983; 33: 21-4.

32 Schultzberg M, Hokfelt T, Lundberg JM, Terenius L, Elfvin LG, Elde R. Enkephalin-like immunoreactivity in nerve terminals in sympathetic ganglia and adrenal medulla and in adrenal medullary gland cells. Acta Physiol Scand 1978; 103: 475-7.

33 Polak JM, Bloom SR, Sullivan SN, Facer P, Pearse AGE. Enkephalin-like immunoreactivity in the human gastrointestinal tract. Lancet 1977; i: 972-4.

34 Smith R, Grossman A, Gaillard R, et al. Studies on circulating met-enkephalin and b-endorphin: normal subjects and patients with renal and adrenal disease. Clin Endocrinol 1981; 15: 291-300.

35 Thornton JR, Dean H, Losowsky MS. Do increased catecholamines and plasma methionine enkephalin in cirrhosis promote bleeding oesophageal varices? $Q J$ Med 1988 (In press).

36 Shatney $\mathrm{CH}$, Cohen RM, Cohen MR, Imagawa DK. Endogenous opioid activity in clinical hemorrhagic shock. Surg Gynecol Obstet 1985; 160: 547-51.

37 Chernow B, Lake R, Teich S, et al. Hemorrhagic hypotension increases plasma beta-endorphin concentrations in the non-human primate. Crit Care Med 1986; 14: 505-7.

38 Thornton JR, Losowksy MS. A role for the kidneys and liver in plasma beta-endorphin elimination? Clin Sci 1988; 74 [Suppl 18]: 51P.

39 Cryer PE. Isotope-derivative measurements of plasma norepinephrine and epinephrine in man. Diabetes 1976; 25: $1071-85$.

40 Lake CR, Ziegler MG, Kopin IJ. Use of plasma norepinephrine for evaluation of sympathetic neuronal function in man. Life Sci 1976; 18: 1315-25.

41 Grossman SH, Davis D, Gunnels JC, Shand DG. Plasma norepinephrine in the evaluation of baroreceptor function in humans. Hypertension 1982; 4: 566-71.

42 Schrier RW, Berl T, Anderson RJ. Osmotic and nonosmotic control of vasopressin release. Am J Physiol 1979; 236: F321-32.
43 Blendis LM, Sole MJ, Campbell P, et al. The effect of peritoneovenous shunting on catecholamine metabolism in patients with hepatic ascites. Hepatology 1987: 7: $143-8$.

44 Keller U, Gerber PPG, Buhler FR, Stauffacher W. Role of the splanchnic bed in extracting circulatory adrenaline and noradrenaline in normal subjects and in patients with cirrhosis of the liver. Clin Sci 1984; 67: 45-9.

45 Willett I, Esler M, Burke F, Leonard P, Dudley F. Total and renal sympathetic nervous system activity in alcoholic cirrhosis. J Hepatol 1985; 1: 639-48.

46 Kew M. Renal changes in cirrhosis. Gut 1972; 13: 748-53.

47 Smythe C McC, Nickel JF, Bradley SE. The effect of epinephrine, 1-epinephrine and 1-norepinephrine on glomerular filtration rate, renal plasma flow and the urinary excretion of sodium, potassium and water in normal man. J Clin Invest 1952; 31: 499-506.

48 Gombos EA, Hulet WH, Bopp P, Goldring W, Baldwin DS, Chasis H. Reactivity of renal and systemic circulations to vasoconstrictor agents in normotensive and hypertensive subjects. J Clin Invest 1962; 41: 203-17.

49 Barger AC, Herd JA. The renal circulation. $N$ Engl J Med 1971; 284: 482-90.

50 Bichet DG, Van Putten VJ, Schrier RW. Potential role of increased sympathetic activity in impaired sodium and water excretion in cirrhosis. N Engl J Med 1982; 307: 1552-7.

51 Epstein M. Deranged sodium homeostasis in cirrhosis. Gastroenterology 1979; 76: 622-35.

52 Bender MD, Ockner RK. Ascites. In: Sleisenger MH, Fordtran JS, eds. Gastrointestinal disease. Pathophysiology, diagnosis, management. Philadelphia: WB Saunders, 1983: 335-55.

53 Zeppa R, Womack NA. Humoral control of hepatic lymph flow. Surgery 1963; 54: 37-44.

54 Sugiyama K. Histamine release induced by dynorphin(1-13) from rat mast cells. Jpn J Pharmacol 1984; 35: 247-52.

55 Casale TB, Bowman S, Kaliner M. Induction of human cutaneous mast cell degranulation by opiates and endogenous opioid peptides: evidence for opiate and non-opiate receptor participation. $J$ Allergy Clin Immunol 1984; 73: 775-81. 